\title{
Evaluation of Lipid Peroxidation and Some Antioxidant Activities in Patients with Primary and Metastatic Liver Cancer
}

\author{
Ayse Arslan $^{1}$, Halit Demir ${ }^{1}$, M. Fatih Ozbay ${ }^{2}$, Harun Arslan ${ }^{3}$ \\ ${ }^{1}$ Department of Biochemistry, Faculty of Science, Yuzuncu Yil University, Van, Turkey; ${ }^{2}$ Department of Internal Medicine, Training \\ and Research Hospital, Van, Turkey; ${ }^{3}$ Training and Research Hospital, Department of Radiology, Van, Turkey. \\ Email: aysearslan@yyu.edu.tr
}

Received January $2^{\text {nd }}, 2014$; revised February $1^{\text {st }}, 2014$; accepted February $9^{\text {th }}, 2014$

Copyright (C) 2014 Ayse Arslan et al. This is an open access article distributed under the Creative Commons Attribution License, which permits unrestricted use, distribution, and reproduction in any medium, provided the original work is properly cited. In accordance of the Creative Commons Attribution License all Copyrights (c) 2014 are reserved for SCIRP and the owner of the intellectual property Ayse Arslan et al. All Copyright (C) 2014 are guarded by law and by SCIRP as a guardian.

\begin{abstract}
Abstract: HCC is the 6th most common cancer in the world. The main risk factors associated with HCC are hepatitis B (HBV) and hepatitis C viral infections and other factors that play a role in HCC development, include aflatoxin B1 (AFB1) cigarette smoking, and chronic inflammation. The aim of this study is to investigate lipid peroxidation and some antioxidant enzyme activities in patients with primary and metastatic liver cancer. For this purpose, 25 primary and metastatic liver cancer patients and 15 healthy controls were included in the study. In blood samples taken from the patient and control groups, the main product of lipid peroxidation MDA and SOD, GSH, GPx activity levels were examined. In result of study serum MDA level is higher and erythrocyte SOD, GSH, and GPX activities were found to be significantly lower in the patient group compared with the control group $(p<0.05)$. As a result, liver cancer is associated with oxidative stress and antioxidant system weakens, which is an important indicator of oxidative stress, lipid peroxidation levels increased and promotes the tissue damage.
\end{abstract}

\section{KEYWORDS}

\section{Primary and Metastatic Liver Cancer; Lipid Peroxidation; Antioxidant Enzymes}

\section{Introduction}

HCC is the sixth most common cancer in the world. Comprising $9.2 \%$ of all cancer-related deaths, it is also the third amongst cancers with high mortality rates [1]. It is known that 630,000 new HCC incidents occur around the world every year [2]. The most significant risk factor in the formation of liver cancer is liver cirrhosis. Liver cirrhosis is responsible for $90 \%$ of liver cancer cases. Aside from these, chronic viral hepatic infections (HBC and $\mathrm{HCV}$ ), alcohol-cigarette consumption, aflatoxin $\mathrm{B}_{1}$, p53 gene mutations, chronic inflammation, genetic diseases, such as alpha-l-antitripcine deficiency, hemochromatosis and diabetes can be cited as significant risk factors [3-5].

Reactive oxygen species (ROS) are superoxide radi- cals $\left(\mathrm{O}_{2}{ }^{-}\right)$, hydrogen peroxide $\left(\mathrm{H}_{2} \mathrm{O}_{2}\right)$, hydroxyl radicals $\left(\mathrm{OH}^{-}\right)$and singlet oxygen which occur in small amounts during normal oxygen metabolism. Reactive oxygen species can initiate free radical chain reactions where various free radicals form [6]. Activation of macrophage and neutrophils and the electron transport chain due to ultraviolet rays, metal catalysed reactions, atmospheric pollution and inflammation are the factors that cause ROS production [7]. Increase in oxygen molecules that can happen at certain levels is deactivated by the natural antioxidant molecules which are always present in certain amounts in the body. This allows the oxidant levels and the deactivation power of antioxidants in an organism to remain in balance [6]. The delicate balance between free radicals and antioxidant defense system shifting in favor of pro-oxidant and oxidants, leads to the development of 
oxidative stress [8,9]. It has been proposed that oxidative stress plays an important role in the progress and development of various cancer types, including liver cancer [10].

Toxic and reactive aldehyde metabolites, such as MDA, which are the end product of lipid peroxidation, form as a result of the interaction between ROS and polyunsaturated fatty acids. MDA may interact with functional groups of various cellular components and promote tumor formation [11]. It is known that lipid peroxidation plays an important role in many diseases, particularly aging, coronary heart diseases and cancer [12]. Some studies report an increase of lipid peroxidation in tumors. Lipid hydrogen peroxides can directly break the DNA chain and lipid peroxyl and alkoxide radicals can cause oxidation in DNA [13].

Free oxygen radicals are primarily removed by various enzymatic antioxidants, such as superoxide dismutase (SOD EC 1.15.1.1), glutathione peroxidase $\left(\mathrm{GP}_{\mathrm{X}} \mathrm{EC}\right.$ 1.11.1.9), catalase (CAT EC 1.11.1.6) and by various non-enzymatic antioxidants, such as glutathione (GSH), a-tocopherol and vitamin C [14]. Superoxide dismutase (SOD) is an important element that protects cells from free oxygen radical toxicity. SOD catalyses the dismutation of superoxide radicals into hydrogen peroxide and molecular oxygen [15]. Glutathione peroxidase (GPx) is the enzyme responsible for reducing hydroperoxides. This is a cytosolic enzyme of tetrameric structure that contains four selenium atoms [16]. GPx that uses glutathione as a substrate, plays an important role in defense against free oxygen radicals, peroxides and carcinogens. $[17,18]$. Glutathione is a tripeptide consisting of glutamic acid, cysteine and glycine and has a high level of intracellular concentration. Glutathione, a significant reduction agent and antioxidant, sustains the oxido-reduction balance of cells and protects them from the negative effects of endogenous and exogenous source oxidants $[19,20]$. Glutathione and relevant enzymes in cells act to deactivate endogenous and exogenous toxic components, free radicals, and reactive oxygen species, such as peroxides that cause damage to the liver and other tissues [21]. A reduction in antioxidants can disrupt the balance between pro and antioxidants and cause cellular damage and resulting malign transformation. Moreover, an oxidative environment with excessive ROS production can affect critical cellular structures, including chromosomes that regulate gene expression [22].

While studies have been made on many cancer types involving lipid peroxidation and antioxidant enzyme levels in blood and tissues samples, studies on blood samples for liver cancer are limited. This study has been conducted to determine serum lipid peroxidation and some antioxidant enzymes activity in primary and metastatic liver cancer patients and their relation to liver cancer.

\section{Materials and Methods}

Twenty-five liver cancer patients and 15 healthy individuals were included in this study. The blood samples used in the study were obtained from patients diagnosed with liver cancer as a result of radiological and histopathological evaluation on referral to the YuzuncuYıl University Faculty of Medicine Education, Research and Application Hospital Oncology Clinic and healthy individuals. Cancer patients and control group similar in terms of age and gender. The cancer patient group was aged between 50 and 75 (mean age 62), consisting of 7 female and 18 male patients. The healthy individuals comprising the control group consisted of six female and nine male patients while the age range was determined as 40 and 65 (mean age 52). Upon examination of the histopathological types of cancer cases, 4 patients were determined to have primary liver cancer and 21 metastatic (stomach, colon, small intestine) liver cancer. While cancer patients had no regular consumption of alcohol or medicine, $28 \%$ of patients were regular smokers. In turn, $15 \%$ of the control group individuals were regular smokers. Cancer cases were newly diagnosed patients whom weren't to receive chemotherapy and radiotherapy. The consent of the Van Bolge Training and Research Hospital Local Ethics Committee was obtained before collecting the blood samples for this study.

Biochemical analysis was performed by the Biochemistry Laboratory of the Chemistry Department, Faculty of Science, Yuzuncu Yil University. The venous blood samples of patient and control group were obtained from the antecubital fossa vein in accordance with the guidelines mentioned in the Declaration of Helsinki. Fasting blood samples were obtained from all subjects and collected into tubes with anticoagulant. Serum was separated by centrifugation (serum was obtained by centrifugation at $2500 \mathrm{rpm}$ for 15 minutes) and the samples were processed immediately. The serum samples were placed in deionized polyethylene tubes and kept at $-80^{\circ} \mathrm{C}$ in a deep-freeze (without thawing) until the day of study. The serum MDA levels were determined as oxidative stress markers. Activities of superoxide dismutase (SOD), glutathione peroxidase $\left(\mathrm{GP}_{\mathrm{X}}\right)$ and glutathione $(\mathrm{GSH})$ in erythrocytes were also measured as markers of the antioxidant system. Red blood cells, separated from serum, were washed three times with cold physiological saline and with demineralized water prior to analysis of hemoglobin and enzyme activities.

MDA was estimated by measuring TBARS (thiobarbituric acid-reactive substances) in serum samples according to a modified method of [23]. Briefly, $0.2 \mathrm{ml}$ of serum was added to the reaction mixture containing $1 \mathrm{ml}$ of $1 \%$ ortho-phosphoric acid, $0.25 \mathrm{ml}$ alkaline solution of thiobarbituric acid-TBA (final volume $2.0 \mathrm{ml}$ ) followed by $45 \mathrm{~min}$ heating at $95^{\circ} \mathrm{C}$. The results were expressed as 
nmol MDA per milliliter of plasma.

SOD was measured spectrophotometrically according to the GSH-400 and SOD-525 methods and assay conditions developed by Bioxytech S.A. Company (Cedex, France). SOD activivity was measured with Randox Ransod enzyme kit with autoanalyzer at $505 \mathrm{~nm}$ and $37^{\circ} \mathrm{C}$. It was determined in red blood cell. $0.1 \mathrm{ml}$ of blood was hemolyzed by $0.9 \mathrm{ml}$ of ice cold water $\left(0^{\circ} \mathrm{C}\right.$ $4^{\circ} \mathrm{C}$ ). The hemoglobin was removed by adding $0.25 \mathrm{ml}$ of chloroform and $0.5 \mathrm{ml}$ of ethanol followed by vigorous mixing and then mixture was centrifuged at 18,000 for $60 \mathrm{~min}$. The rate of inhibition of the superoxide reaction by SOD was calculated according to the definition of McCord and Fridovich (1969) [24].

$\mathrm{GP}_{\mathrm{x}}$ enzyme activity was measured with commercial kits in a DU-640 spectrophotometer (Beckman Instruments, California, USA). GPx activities were spectrophotometrically assayed in erythrocytes $\mathrm{GP}_{\mathrm{X}}$ [25]. $\mathrm{GP}_{\mathrm{X}}$ activity was measured in erythrocyte by using a Hitachi 902 Autoanalyzer (Hitachi, Brisbane, CA) with Randox's reagent (San Diego, CA). Results were indicated per milliliter of whole blood. When the oxide glutathion is reduced, NADPH is oxidized and it is turned into NADP. This change was observed at $340 \mathrm{~nm}$ wave and activation of GPx was measured. The intra-assay and inter assay CV for GPx were $5.2 \%$ and $7.2 \%$, respectively. Units of GPx activity were calculated following NADPH oxidation at $340 \mathrm{~nm}$ using cumene hydroperoxide as the substrate.

The GSH level was measured spectrophotometrically at $412 \mathrm{~nm}$ by a glutathione disulfide reductase recycling method at room temperature. Reference rate was established using a freshly prepared GSH standard $(30 \mathrm{mmol})$ [26].

\section{Statistical Analysis}

Statistical evaluation was performed using the SPSS ${ }^{\circledR}$ statistical software package (SPSS for Windows version 13.0, SPSS Inc., Chicago, Illinois, USA). Data obtained from the study groups were compared use the Student- $t$ test. The results were expressed as mean \pm standard deviation and $\mathrm{p}<0.05$ value was considered statistically significant.

\section{Results}

The defining characteristics of individuals participating in our study have been provided in Table 1 . Individuals in the patient and control groups were selected from amongst persons of similar age and gender. As a result of radiological and histopathological evaluations, 4 of the patient group individuals were found to have primary cancer while 21 had metastatic liver cancer. While smoking in the patient group was an average of $26 \%$, this
Table 1. Defining characteristics of individuals participating in the study.

\begin{tabular}{ccc}
\hline & $\begin{array}{c}\text { Patient Group } \\
(\mathbf{n}=\mathbf{2 5})\end{array}$ & $\begin{array}{c}\text { Control Group } \\
(\mathbf{n}=\mathbf{1 5})\end{array}$ \\
\hline Age range (years) & $50-75$ & $40-65$ \\
Female & 7 & 6 \\
Male & 18 & 9 \\
Primary liver cancer & 4 & - \\
Metastatic liver cancer & 21 & - \\
Smoking use & $\% 26$ & $\% 15$ \\
Alcohol use & none & none \\
\hline
\end{tabular}

rate was around $15 \%$ for the control group. Neither group had alcohol consumption.

Table 2 lists the biochemical parameters of patient and control groups. As can be seen in Table 2, SOD, GSH and GPx values of the primary and metastatic liver cancer patient group were found to be significantly lower (p $<0.05$ ) when compared to the control group. Despite this, the MDA value in the patient group was found to be significantly higher $(\mathrm{p}<0.05)$ when compared to the control group.

\section{Discussion}

The pathophysiology of cancer has not yet been fully clarified up to date; but strong evidence exists showing the important role of free radicals in this complex process. Free radicals are high energy, unstable components including electrons without one or more pairs in their external atomic orbitals. This unpaired electron provides free radicals with great reactivity and causes them to damage many biological materials, such as protein, lipids, DNA and nucleotide coenzymes. As a result, many diseases, such as aging, cardiovascular diseases, various cancer types, cataract and degenerative neurological diseases are thought to be caused by free radical damage [27].

Toxic and reactive aldehyde metabolites, such as MDA, which are the end product of lipid peroxidation, form as a result of the interaction between ROS and polyunsaturated fatty acids [11]. MDA is an important indicator of oxidative stress. It has been suggested that free oxygen radical-mediated lipid peroxidation is related to malign transformation, promotes the tumor due to high toxic effect and acts as a co-carcinogenic agent [28,29]. Our study has determined that serum MDA levels of primary and metastatic liver cancer patients are significantly higher than the control group. A study performed on HCC patients has also found significantly higher serum MDA levels than the control group [30]. Studies performed in various cancer types have shown varying results. Serum MDA levels were found to be lower in colorectal carcinoma patients [31], higher in lung cancer 
Table 2. Biochemical results of patient and control groups.

\begin{tabular}{lcccc}
\hline & SOD $(\mathrm{EU} / \mathrm{mL})$ & GSH $(\mathrm{mmol} / \mathrm{g} \mathrm{Hb})$ & GPx $(\mathrm{EU} / \mathrm{mL})$ & MDA $(\mathrm{nmol} / \mathrm{ml})$ \\
\hline Patient Group $(\mathrm{n}=25)$ & $24.3820 \pm 10.0242^{*}$ & $42.2540 \pm 1.9148^{*}$ & $40.2016 \pm 0.6703^{*}$ & $41.5408 \pm 2.1120^{*}$ \\
Control Group $(\mathrm{n}=15)$ & $42.4293 \pm 3.2770$ & $86.7033 \pm 2.3795$ & $77.7687 \pm 2.2842$ & $20.3847 \pm 0.7595$ \\
\hline
\end{tabular}

Values were shown as mean and $( \pm)$ standard deviation. "Shows the statistical significance between the patient group and control group $(\mathrm{p}<0.05)$.

patients [32] and lower in breast cancer patients [33]. The high lipid peroxidation in liver cancer may be due to excessive ROS production. MDA may react with the amino acid residue of proteins, resulting in their oxidative modification and causing protein breakdown in the process. Moreover, it may encourage cellular use of glutathione and increase oxidative stress by deactivating selenium dependent glutathione peroxidases [34,35]. These enzymes by inhibiting MDA in liver cancer may lead oxidative stress and therefore increase cellular damage.

Antioxidants play a preventive role against cancer by directly removing free radicals or inhibiting processes that cause free radical production [36,37]. Superoxide dismutase, Glutathione peroxidase and Catalase are the primary intracellular significant enzymes that have the ability to eliminate free radicals. These enzymes generally prevent free radicals from damaging cellular components, such as DNA, proteins and lipids [27]. SOD catalyses the dismutation of superoxide anions into hydrogen peroxide and comprises the first enzymatic defense line against free oxygen radicals [38]. Glutathioneisa reducing agentcommonly found incells. It is also a metabolic regulator and is considered to be an important indicator of health. It is believed that blood glutathione levels are determinant in morbidity and mortality [39]. Glutathione peroxidase also catalyses the reduction of hydrogen peroxide and organic hydroperoxides simultaneously with the oxidation of GSH [22]. Glutathione and GPx protect cells from damage by reducing the negative effects of lipid peroxidation on the membrane [40]. It has been suggested that low levels of main antioxidants in the circulating may lead increase the risk of cancer [41].

In our study we found that the erythrocyte SOD, GSH and GPx activity of primary and metastatic liver cancer patients to be lower in comparison to the control group. Similarly with our study, another study was found that the antioxidant levels plasma SOD, GSH and GPx levels were lower than the control group in patients with HCC [30]. Mean while Lee et al. (2007) found that glutathione levels in blood and cancer tissue samples of HCC patients were significantly lower [42]. It has been suggested that low levels of glutathione can be related to the dysfunction of the damaged liver and ultimately with a decrease tripeptide synthesis [43]. Moreover, information exists in various studies that alcohol use causes liver damage and thus decreases GSH levels. [44]. However, none of the individuals participating in our study were alcohol consumers. Abel et al. (2009) found low GSH levels and higher SOD and GPx activity in the cancer tissue of HCC patients [45]. Scibior et al. (2008) found higher serum GPx activity in HCC patients when compared to the control group in the pre and post-surgery periods and argued that this is an adaptive response to oxidative stress. The same study also found no difference between patient and control groups in terms of GSH activity [46]. Upon reviewing the results of these studies, it is observed that antioxidant activities in blood and tissue samples of liver cancer cases vary.

Studies on various cancer types have also obtained varying results. While Chang et al. (2008) found low serum SOD and GPx levels in colorectal carcinoma patients, they determined that GSH levels do not vary between patient and control groups [31]. A study on lung cancer patients found higher SOD levels in the patient group while a variation in GPx activity was not detected [32]. Another study on the antioxidant levels of gastrointestinal cancer patients (stomach, liver, colon etc.) showed high GSH and low SOD levels in the patient group, meanwhile GPx levels were found to be unvarying between the patient and control group [47].

In conclusion, antioxidant enzyme activities and lipid peroxidation levels vary in different cancer types. The reduction of antioxidant activity in liver cancer may encourage lipid peroxidation due to excessive ROS production and cause to increase oxidative damage severity. The increased use of antioxidants for the removal of lipid peroxides and sequestration of antioxidants from the blood stream by tumor cells may cause a reduction of antioxidants [17]. However, further research is needed to clarify the question whether decreased of antioxidants is the result or the cause of the cancer process and to better understand lipid peroxidation in this complex process.

\section{REFERENCES}

[1] J. Ferlay, H. R. Shin, F. Bray, D. Forman, C. Mather and D. M. Parkin, "Estimates of Worldwide Burden of Cancer in 2008: Globocan 2008," International Journal of Cancer, Vol. 127, No. 12, 2010, pp. 2893-2917. http://dx.doi.org/10.1002/ijc.25516

[2] H. B. El-Serag, “Hepatocellular Carcinoma,” New England Journal of Medicine, Vol. 365, No. 12, 2011, pp. 1118-1127. http://dx.doi.org/10.1056/NEJMra1001683

[3] R. Mazzanti, L. Gramantieri and L. Bolondi, "Hepatocellular Carcinoma: Epidemiology and Clinical Aspects,” Molecular Aspects of Medicine, Vol. 29, No. 1-2, 2008, 
pp. 130-143. http://dx.doi.org/10.1016/j.mam.2007.09.008

[4] C. Müller, "Hepatocellular Carcinoma-Rising İncidence, Changing Therapeutic Strategies," Wiener Medizinische Wochenschrift, Vol. 156, No. 13-14,2006, pp. 404-409. http://dx.doi.org/10.1007/s10354-006-0316-3

[5] N. K. Tangutur, S. F. Medvedev, F. Regenstein and L. A. Balart, "Hepatocellular Carcinoma, a Rapidly İncreasing Public Health Problem: The Tulane Experience 20032009," The Journal of the Louisiana State Medical Society,Vol. 163, No. 4, 2011, pp. 185-190.

[6] B. Halliwell, "Reactive Oxygen Species in Living Systems: Source, Biochemistry and Role in Human Disease," American Journal of Medicine, Vol. 91, No. 3C, 1991, pp.14-22. http://dx.doi.org/10.1016/0002-9343(91)90279-7

[7] E. Cadenas, "Biochemistry of Oxygen Toxicity,” Annual Review of Biochemistry, Vol. 58, 1989, pp. 79-110. http://dx.doi.org/10.1146/annurev.bi.58.070189.000455

[8] C. E. Cross, B. Halliwell, E. T. Borish, W. A. Pryor, B. N. Ames, et al., "Oxygen Radicals and Human Disease," Annals of Internal Medicine, Vol. 107, No. 4, 1987, pp. 526545. http://dx.doi.org/10.7326/0003-4819-107-4-526

[9] K. Asayama, T. Nakane, H. Uchida, H. Hayashibe, K. Dobashi and S. Nakazawa, "Serum Antioxidant Status in Streptazosin-İnduced Diabetic Rat,” Hormone and Metabolic Research, Vol. 26, No. 7, 1994, pp. 617-620. http://dx.doi.org/10.1055/s-2007-1001693

[10] R. K. Ockner, R. M. Kaikaus and N. M. Bass, "Fatty-Acid Metabolism and the Pathogenesis of Hepatocellular Carcinoma: Review and Hypothesis," Hepatology, Vol. 18, No. 3, 1993, pp. 669-676.

[11] C. E.Vaca, J. Wilhelm and M. Harms-Ringdal, "Interaction of Lipid Peroxidation Products with DNA. A Review," Mutation Research, Vol. 195, No. 2, 1988, pp. 137149. http://dx.doi.org/10.1016/0165-1110(88)90022-X

[12] K. Ueda, S. Kobayashi, J. Morita and T. Komano, "Sitespecific DNA Damage Caused by Lipid Peroxidation Products,” Biochim Biophys Acta, Vol. 824, No. 4, 1985, pp. 341-348. http://dx.doi.org/10.1016/0167-4781(85)90041-7

[13] C. G. Cochrane, “Cellular İnjury by Oxidants,” American Journal of Medicine, Vol. 91, No. 3C, 1991, pp. 23-30. http://dx.doi.org/10.1016/0002-9343(91)90280-B

[14] J. Gromadizinka, W. Wasowichz, M. Andrijewski, M. Sklodowska, et al., "Glutathione and Glutathione Metabolizing Enzymes in Tissue and Blood of Breast Cancer Patients,” Neoplasma, Vol. 44, No. 1, 1997, pp. 45-51.

[15] A. Klimczak, K. Kubiak, M. Cybulska, A. Kula, L. Dziki, et al., "Etiology of Colorectal Cancer and antioxidant Barrier of the Organism,” Pol Merkur Lekarski, Vol. 28, No. 65, 2010, pp. 223-226.

[16] H. R. Andersen, J. B. Nielsen, F. Nielsen and P. Grandjean, "Antioxidative Enzyme Activities In Human Erithrocytes,” Clinical Chemistry, Vol. 43, No. 4, 1997, pp. 562-568.

[17] R. Kumaraguruparan, R. Subapriya, J. Kabalimoorthy and S. Nagini, "Antioxidant Profile in the Circulation of
Patients with Fibroadenoma and Adenocarcinoma of the Breast," Clinical Biochemistry, Vol. 35, No. 4, 2002, pp. 275-279. http://dx.doi.org/10.1016/S0009-9120(02)00310-7

[18] E. Serin, E. Y1lmaz,. S. Yılmaz, E. Ünsaldı and A. S. Durmuş, "Ischemia-Reperfusion İnjury by Oxygen Free Radicals,” Arthroplasty Arthroscopic Surgery, Vol. 9, 1998, pp. 36-39.

[19] J. B. Mitchel and A. Russo, "The Role of Glutathione in Radiation and Drug İnduced Cytotoxicity,” The British Journal of Cancer. Supplement, Vol. 8, 1987, pp. 96-104.

[20] M. Y. Farooqui, W. W. Day and D. M. Zamorano, "Glutathione and Lipid Peroxidation in the Aging Rat," Comparative Biochemistry and Physiology Part B: Comparative Biochemistry, Vol. 88, No. 1, 1987, pp. 177-180. http://dx.doi.org/10.1016/0305-0491(87)90097-6

[21] J. D. Hayes and L. I. Mclellan, "Glutathione and Glutathione Dependent-Enzymes Represent a Co-Ordinately Regulated Defence against Oxidative Stress," Free Radical Research, Vol. 31, No. 4, 1999, pp. 273-300. http://dx.doi.org/10.1080/10715769900300851

[22] C. Lindholm, A. Acheva and S. Salomaa, "Clastogenic Plasma Factors: A Short Overview,” Radiation and Environmental Biophysics, Vol. 49, No. 2, 2010. pp. 133-138. http://dx.doi.org/10.1007/s00411-009-0259-3

[23] A. M. Jentzsch, H. Bachmann, P. Fürst and H. K. Biesalski, "Improved Analysis of Malondialdehyde in $\mathrm{Hu}-$ man Body Fluids," Free Radical Biology \& Medicine, Vol. 20, No. 2, 1996, pp. 251-256. http://dx.doi.org/10.1016/0891-5849(95)02043-8

[24] J. M. McCord and I. Fridovich, "Superoxide Dismutase: An Enzymic Function for Erythrocuprein (Hemocuprein), Journal of Biological Chemistry, Vol. 244, No.22, 1969, pp. 6049-6055.

[25] D. E. Paglia and W. N. Valentıne, "Studies on the Quantitative and Qualitative Characterisation of Erytrocyte Glutahione Peroxidase,” Journal of Laboratory and Clinical Medicine, 1967, Vol. 70, No. 1, 1967, pp. 158-169.

[26] F. Tietz, "Enzymic Method for Quantitative Determination of Nanogram Amounts of Total and Oxidized Glutathione: Applications to Mammalian Blood and Other Tissues,” Analytical Biochemistry, Vol. 27, No. 3, 1969, pp. 502-522. http://dx.doi.org/10.1016/0003-2697(69)90064-5

[27] A. T. Diplock, "Healty Lifestyles Nutrition and Physical Activity: Antioxidant Nutrients," ILSI Europe Concise Monograph Series, Belgium, 1998, p. 59.

[28] R. A. Gonzalez, "Free Radicals, Oxidative Stress and DNA Metabolism in Human Cancer," Cancer Investigation, Vol. 17, No. 5, 1999, pp. 376-377. http://dx.doi.org/10.3109/07357909909032882

[29] L. J. Marnett, "Lipid Peroxidation-DNA Damage by Malondialdehyde," Mutation Research, Vol. 424, No. 1-2, 1999, pp. 83-95.

http://dx.doi.org/10.1016/S0027-5107(99)00010-X

[30] C. C. Lin and M. C. Yin, "B Vitamins Deficiency and Decreased Anti-Oxidative State in Patients with Liver Cancer,” European Journal of Nutrition, Vol. 46, No. 5, 
2007, pp. 293-299.

http://dx.doi.org/10.1007/s00394-007-0665-8

[31] D. Chang, F. Wang, Y. S. Zhao and H. Z. Pan, "Evaluation of Oxidative Stress in Colorectal Cancer Patients," Biomedical and Environmental Sciences, Vol. 21, No. 4, 2008, pp. 286-289.

http://dx.doi.org/10.1016/S0895-3988(08)60043-4

[32] H. Kaynar, M. Meral, H. Turhan, M. Keles, G. Celik et al., "Glutathione Peroxidase, Glutathione-S-Transferase, Catalase, Xanthine Oxidase, Cu-Zn Superoxide Dismutase Activities, Total Glutathione, Nitric Oxide, and Malondialdehyde Levels in Erythrocytes of Patients with Small Cell and Non-Small Cell Lung Cancer," Cancer Letters, Vol. 227, No. 2, 2005, pp. 133-139. http://dx.doi.org/10.1016/j.canlet.2004.12.005

[33] C. C. Yeh, M. F. Hou, S. M. Tsai, S. K. Lin, J. K. Hsiao, J. C. Huang, et al., "Superoxide Anion Radical, Lipid Peroxides and Antioxidant Status in the Blood of Patients with Breast Cancer," Clinica Chimica Acta, Vol. 361, No. 1-2, 2005, pp. 104-111. http://dx.doi.org/10.1016/j.cccn.2005.05.002

[34] L. J. Niederhofer, J. S. Daniels, C. A. Rauzer, R. E. Greene and L. J. Marnett, "Malonaldehyde, a Product of Lipid Peroxidation İs Mutagenic in Human Cells," The Journal of Biological Chemistry, Vol. 278, No. 3, 2003, pp. 31426-31433. http://dx.doi.org/10.1074/jbc.M212549200

[35] L. J. Marnett, “Oxy Radicals, Lipid Peroxidation and DNA Damage,” Toxicology, No. 181/182, 2002, pp. 219222. http://dx.doi.org/10.1016/S0300-483X(02)00448-1

[36] S. P. Hussain, L. J. Hofseth and C. C. Harris, "Radical Causes of Cancer,” Nature Reviews Cancer, Vol. 3, No. 4, 2003, pp. 276-285. http://dx.doi.org/10.1038/nrc1046

[37] C. Nicco, A. Laurent, C. Chereau, B. Weill and F. Batteux, "Differential Modulation of Normal and Tumor Cell Proliferation by Reactive Oxygen Species,” Biomedicine \& Pharmacotherapy, Vol. 59, No. 4, 2005, pp. 169-174. http://dx.doi.org/10.1016/j.biopha.2005.03.009

[38] M. F. Polat, S. Taysi, M. Gul, O. C1kman, I. Yilmaz, E. Bakan and F. Erdogan, "Oxidant/Antioxidant Status in Blood of Patients with Malignant Breast Tumor and Benign Breast Disease,” Cell Biochemistry and Function, Vol. 20, No. 4, 2002, pp. 327-331. http://dx.doi.org/10.1002/cbf.980

[39] C. A. Lang, S. Naryshkin, D. L. Schneider, B. J. Mills and R. D. Lindeman, "Low Blood Glutathione Levels in Healthy Aging Adults,” Journal of Laboratory and Clini- cal Medicine, Vol. 120, No. 5, 1992, pp. 720-725.

[40] L. Masotti, E. Casali, N. Gesmundo, G. Sartor, T. Galeotti, S. Borrello, M. V. Pitetti and G. Pagliuca, "Lipid Peroxidation in Cancer Cells: Chemical and Physical Studies," Annals of the New York Academy of Sciences, Vol. 551, 1988, pp. 47-57. http://dx.doi.org/10.1111/j.1749-6632.1988.tb22319.x

[41] A. T. Diplock, “Antioxidant Nutrients and Disease Prevention: An Overview,” American Journal of Clinical Nutrition, Vol. 53, No. 1, 1991, pp. 189-193.

[42] K. T. Lee, S. M. Tsai, S. N. Wang, S. K. Lin, S. H. Wu, S. C. Chuang, S. H. Wu, H. Ma and L. Y. Tsai, "Glutathione Status in the Blood and Tissues of Patients with VirusOriginated Hepatocellular Carcinoma," Clinical Biochemistry, Vol. 40, No. 15, 2007, pp. 1157-1162. http://dx.doi.org/10.1016/j.clinbiochem.2007.06.012

[43] S. Kikkawa, M. Kadoharaa and H. Kawasaki, "Superoxide Dismutase and Glutathione in the Gastric Mucosa of Patients with Chronic Liver Disease,” Research Communications in Chemical Pathology and Pharmacology, Vol. 78, No. 3, 1992, pp. 289-309.

[44] S. S. Chiou, T. T. Chang, S. P. Tsai, R. C. Jang, S. K. Lin, S. C. Lee, S. M. Tsai and L. Y. Tsai, "Lipid Peroxidation and Antioxidative Status in $\beta$-Thalassemia Major Patients with or without Hepatitis C Virus İnfection,” Clinical Chemistry and Laboratory Medicine, Vol. 44, No. 10, 2006, pp. 1226-1233. http://dx.doi.org/10.1515/CCLM.2006.219

[45] S. Abel, M. DeKock, D. J. Vanschalkwyk, S. Swanevelder, M. C. Kew and W. C. A. Gelderblom, "Altered Lipid Profile, Oxidative Status and Hepatitis B Virus İnteractions in Human Hepatocellular Carcinoma,” Prostaglandins, Leukotrienes and Essential Fatty Acids, Vol. 81, No. 5, 2009, pp. 391-399. http://dx.doi.org/10.1016/j.plefa.2009.08.003

[46] D. Ścibior, M. Skrzycki, M. Podsiad and H. Czeczot, "Glutathione Level and Glutathione-Dependent Enzyme Activities in Blood Serum of Patients with Gastrointestinal Tract Tumors," Clinical Biochemistry, Vol. 41, No. 10-11, 2008, pp. 852-858. http://dx.doi.org/10.1016/j.clinbiochem.2008.03.005

[47] A. Gönenç, A. Hacışevki, S. Aslan, M. Torun and B. Şimşek, "Increased Oxidative DNA Damage and İmpaired Antioxidant Defense System in Patients with Gastrointestinal Cancer,” European Journal of Internal Medicine, Vol. 23, No. 4, 2012, pp. 350-354. http://dx.doi.org/10.1016/j.ejim.2012.02.001 